\title{
Procyanidin B2 Alleviates Palmitic Acid-Induced Injury in HepG2 Cells via Endoplasmic Reticulum Stress Pathway
}

\author{
Yi-Ming Li $\mathbb{D}^{1},{ }^{1}$ Shao-Yang Zhao $\mathbb{D}^{1,2}$ Huan-Huan Zhao $\mathbb{D}^{1},{ }^{3}$ Bao-Hua Wang $\mathbb{D}^{1,2}$ \\ and Sai-Mei $\mathrm{Li} \mathbb{D}^{1,2}$ \\ ${ }^{1}$ The First School of Clinical Medicine, Guangzhou University of Chinese Medicine, Guangzhou 510000, China \\ ${ }^{2}$ The First Affiliated Hospital of Guangzhou University of Chinese Medicine, Guangzhou 510000, China \\ ${ }^{3}$ Nutrition Department, Linyi People's Hospital, Linyi 276000, China
}

Correspondence should be addressed to Bao-Hua Wang; wangbaohua@gzucm.edu.cn and Sai-Mei Li; 1sm@gzucm.edu.cn

Received 29 August 2021; Revised 21 November 2021; Accepted 26 November 2021; Published 16 December 2021

Academic Editor: Shao-Hsuan Kao

Copyright (c) $2021 \mathrm{Yi}$-Ming Li et al. This is an open access article distributed under the Creative Commons Attribution License, which permits unrestricted use, distribution, and reproduction in any medium, provided the original work is properly cited.

Nonalcoholic fatty liver disease (NAFLD) is the hepatic manifestation of the metabolic syndrome featuring ectopic lipid accumulation in hepatocytes. NAFLD has been a severe threat to humans with a global prevalence of over $25 \%$ yet no approved drugs for the treatment to date. Previous studies showed that procyanidin B2 (PCB2), an active ingredient from herbal cinnamon, has an excellent hepatoprotective effect; however, the mechanism remains inconclusive. The present study aimed to investigate the protective effect and underlying mechanism of PCB2 on PA-induced cellular injury in human hepatoma HepG2 cells. Our results showed that PA-induced oxidative stress, calcium disequilibrium, and subsequent endoplasmic reticulum stress (ERS) mediated cellular injury, with elevated protein levels of GRP78, GRP94, CHOP, and hyperphosphorylation of PERK and IRE1 $\alpha$ as well as the increased ratio of $\mathrm{Bax} / \mathrm{Bcl}-2$, which was restored by $\mathrm{PCB} 2$ in a concentration-dependent manner, proving the excellent antiapoptosis effect. In addition, 4-phenylbutyric acid (4-PBA), the ER stress inhibitor, increased cell viability and decreased protein levels of GRP78 and CHOP, which is similar to PCB2, and thapsigargin (TG), the ER stress agonist, exhibited conversely meanwhile partly counteracted the hepatic protection of PCB2. What is more, upregulated protein expression of $\mathrm{p}-\mathrm{IKK} \alpha / \beta, \mathrm{p}-\mathrm{NF}-\kappa \mathrm{B}$ p 65 , NLRP3, cleaved caspase 1 , and mature IL-1 $\beta$ occurred in HepG2 cells in response to PA stress while rescued with the PCB2 intervention. In conclusion, our study demonstrated that PA induces ERS in HepG2 cells and subsequently activates downstream NLRP3 inflammasome-mediated cellular injury, while PCB2 inhibits NLRP3/caspase 1/IL-1 $\beta$ pathway, inflammation, and apoptosis with the presence of ERS, thereby promoting cell survival, which may provide pharmacological evidence for clinical approaches on NAFLD.

\section{Introduction}

Nonalcoholic fatty liver disease (NAFLD) is a chronic pathological syndrome caused by excessive lipid accumulation in hepatocytes and steatosis $[1,2]$, including a spectrum from simple steatosis to nonalcoholic steatohepatitis (NASH), and may progress to cirrhosis and hepatocellular carcinoma $[1,3]$. NAFLD is part of a multisystemic metabolic disorder associated with obesity, type 2 diabetes, and hyperlipidemia [4]. The disease has a global prevalence of over $25 \%$ and poses a serious threat to humans, but to date there are no approved therapeutic drugs [4-6].

Elevated circulating free fatty acids (FFAs) derived from adipose contribute to hepatic lipid accumulation [7-10].
Lipotoxicity of FFA and its metabolites leads to mitochondrial dysfunction, oxidative stress, endoplasmic reticulum stress, and apoptosis $[1,11,12]$, thereby contributing to the development of NASH. Fatty acids are chemically classified as saturated and unsaturated [13], and palmitic acid (PA), the most common circulating saturated fatty acid [14], has been shown to be highly toxic to various cell lines. Previous studies have shown that human hepatoma HepG2 cells exposed to PA are susceptible to oxidative stress and apoptosis [15]; $\mathrm{Ca}^{2+}$ disequilibrium, ERS, and subsequent apoptosis occurred in OUMS-29 (human hepatocyte line) and Huh7 (human hepatocellular carcinomaderived cell line) cells in response to PA stimulation [16]; PA-induced apoptosis in mouse hepatocyte AML-12 cells 
accompanied by ERS and activation of the NOD-like receptor family pyrin domain-containing 3 (NLRP3) inflammasome [17], and an in vitro inflammatory model of AML-12 cells were established in another study [18]. In addition, PA leads to inflammation in rat cardiomyocyte $\mathrm{H} 9 \mathrm{c} 2$ and apoptosis in mouse pancreatic $\beta$-cell NIT-1 due to its cytotoxicity $[19,20]$.

ERS plays a pivotal role in the pathogenesis of NAFLD. Transient deleterious stimulation to the endoplasmic reticulum (ER) causes protein misfolding, ERS, and activation of the unfolded protein response (UPR) to resolve protein folding defects and reestablish the ER homeostasis initially, and conversion to apoptosis upon sustained or massive ERS [21]. ER chaperones, mainly glucose-regulated proteins 78 (GRP78) and 94 (GRP94), dissociate from three ER transmembrane transducers: the protein kinase RNA-like endoplasmic reticulum kinase (PERK), inositol-requiring enzyme $1 \alpha(\operatorname{IRE} 1 \alpha)$, and activating transcription factor $6 \alpha$ $(\mathrm{ATF} 6 \alpha)$. PERK phosphorylates eukaryotic initiation factor $2 \alpha$ (eIF $2 \alpha$ ), which stops mRNA translation in response to stress. Phosphorylation of IRE $1 \alpha$ activates transcription factors XBP1s to enhance both ER protein folding and protein degrading. The activation of ATF $6 \alpha$ implicates in protein degradation as well. Three pathways disturb $\mathrm{Ca}^{2+}$ equilibrium in a Bcl-2 family-dependent manner and upregulate downstream targets [22], particularly C/EBP homologous protein (CHOP), triggering ERS-mediated apoptosis. Briefly, ERS is broadly involved in biological processes such as calcium and redox homeostasis, inflammatory response, activation of the NLRP3 inflammasome, and apoptosis [23].

There is conclusive evidence that palmitic acid (PA) induces ERS and further apoptosis in hepatocytes, and related pharmaceutical studies are well documented. The active ingredients of traditional Chinese decoctions and traditional herbal medicines have also had therapeutic implications in clinical trials and pharmacodynamics. Procyanidin B2 (PCB2), an active ingredient from herbal cinnamon (Cinnamomum cassia) [24], has demonstrated the beneficial effects of antioxidation, anti-inflammation, and antiapoptosis in mammals with NAFLD and other metabolic diseases [25-27]. Yet, research on whether and how PCB2 impacts ERS-mediated injury in PA-induced hepatocytes remains a gap. Hereby, we performed experiments to illustrate the subjects. Using PA-induced HepG2 cells as a model, the effects of PCB2 on ERS and NLRP3 inflammasome were investigated in vitro to provide pharmacological evidence for therapeutic strategies for NAFLD.

\section{Materials and Methods}

2.1. Reagents. Procyanidin B2 (CAS: 29106-49-8, the chemical structure, see Figure 1(a)) and thapsigargin (TG) were obtained from Shanghai Yuanye Bio-Technology Co., Ltd (Shanghai, China). Cell Counting Kit-8 (CCK-8) was purchased from Dojindo Laboratories (Dojindo, Kumamoto, Japan). Detection kits of lactate dehydrogenase $(\mathrm{LDH})$, superoxide dismutase (SOD), malondialdehyde (MDA), and calcium $\left(\mathrm{Ca}^{2+}\right)$ were purchased from
Nanjing Jiancheng Bioengineering Institute (Nanjing, Jiangsu Province, China). Annexin V-FITC/PI Kit was obtained from MultiSciences Biotech Co., Ltd (Hangzhou, Zhejiang Province, China). Terminal deoxynucleotidyl transferase (TdT)-mediated dUTP-biotin nick end-labeling (TUNEL) and ER-Tracker Red staining kits were purchased from Beyotime Biotechnology Co., Ltd (Shanghai, China). 4',6-diamidino-2-phenylindole (DAPI), $2^{\prime}, 7^{\prime}$-dichlorofluorescein diacetate (DCFH-DA), and Hoechst 33342 were obtained from Sigma-Aldrich (Merck KGaA, Darmstadt, Germany). 4-Phenylbutyric acid (4-PBA) was obtained from Shanghai Yien Chemical Technology Co., Ltd (Shanghai, China). Antibodies for p-IRE1 (ab124945, $1: 1000$ ) and NLRP3 (ab263899, 1 : 1000) were purchased from Abcam (Cambridge, UK); p-PERK (bs-3330R, $1: 1000$ ) was purchased from Beijing Biosynthesis Biotechnology Co., Ltd. (Beijing, China); IL$1 \beta$ (sc-12742, 1:200) was obtained from Santa Cruz Biotechnology, Inc. (Dallas, Texas, USA); and GRP78 (\#3177, $1: 1000)$, GRP94 (\#2104, $1: 1000)$, PERK (\#5683, $1: 1000), \mathrm{p}-\mathrm{eIF} 2 \alpha(\# 3398,1: 1000), \mathrm{eIF} 2 \alpha(\# 5324,1: 1000)$, IRE1 $\alpha$ (\#3294, $1: 1000)$, CHOP (\#2895, $1: 1000)$, cleaved caspase 1 (\#4199, 1:1000), Bcl-2 (\#3498, 1:1000), Bax (\#2772, $1: 1000), \mathrm{p}-\mathrm{IKK} \alpha / \beta$ (\#2697, $1: 1000), \mathrm{IKK} \beta$ (\#8943, $1: 1000), \quad \mathrm{p}-\mathrm{NF}-\kappa \mathrm{B}$ p65 (\#3033, $1: 1000), \mathrm{NF}-\kappa \mathrm{B}$ p65 (\#8242, 1:1000), and GAPDH (\#5174, 1:2000) were obtained from Cell Signaling Technology (Danvers, MA, USA).

2.2. Cell Culture. The human hepatoma HepG2 cell line was purchased from the Type Culture Collection Cell Bank, Chinese Academy of Science (Shanghai, China). Cells were maintained in Dulbecco's modified Eagle medium (DMEM; Gibco, CA, USA) supplemented with 10\% (v/v) heat-inactivated fetal bovine serum (FBS; Biological Industries, Israel) and $1 \%(\mathrm{v} / \mathrm{v})$ penicillin-streptomycin (PS, Gibco) in a humidified $5 \% \mathrm{CO}_{2}$ incubator at $37^{\circ} \mathrm{C}$.

2.3. Establishment of Injured HepG2 Model and Cytotoxicity of PCB2. HepG2 cells were exposed to various concentrations of palmitic acid $(50,75,100,125,150,175,200,225$, and $250 \mu \mathrm{M})$ for 8,16 , and $24 \mathrm{~h}$, respectively. When the cell viability decreased to $60 \%-70 \%$, the appropriate injured cell model was established. Then, based on the PA exposure duration, the cytotoxicity of PCB2 from 2.5 to $100 \mu \mathrm{M}$ was assessed.

2.4. Sample Treatment. HepG2 cells were divided into control, model, and PCB2 groups (low, medium, and high concentrations). The control group was cultured in DMEM (4.5 g/L D-glucose) without drug intervention. The model group was exposed to palmitic acid $(125 \mu \mathrm{M})$. The PCB2 groups were co-treated with various concentrations of PCB2 $(2.5,5$, and $10 \mu \mathrm{M})$ and palmitic acid. The drug exposure duration was $24 \mathrm{~h}$ for most experiments. Except where otherwise stated, all experiments were done at the same condition. 
<smiles>Oc1cc(O)c2c(c1)OC(c1ccc(O)c(O)c1)[C@H](O)[C@H]2c1c(O)cc(O)c2c1OC(c1ccc(O)c(O)c1)C(O)C2</smiles>

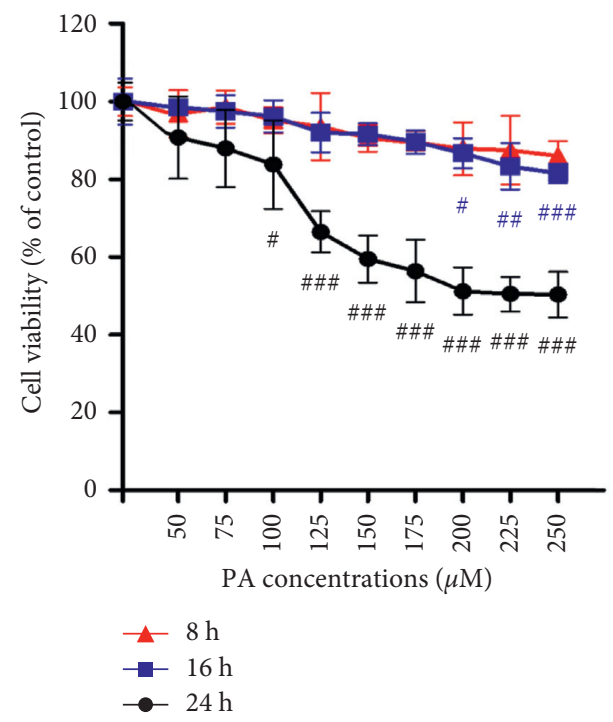

(a)

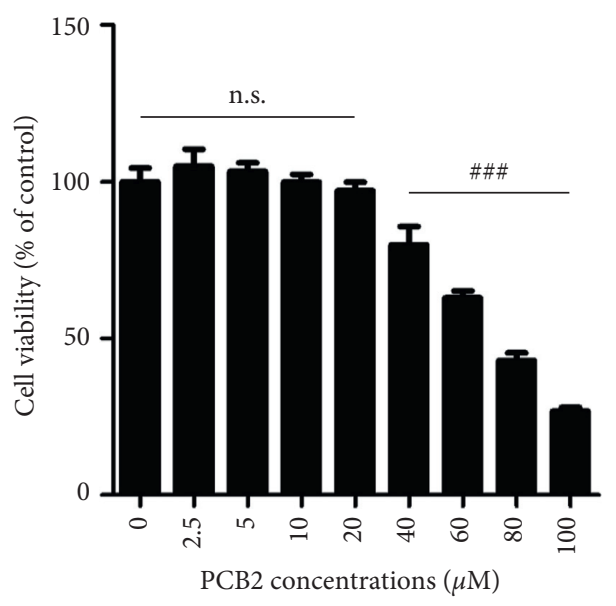

(c) (b)

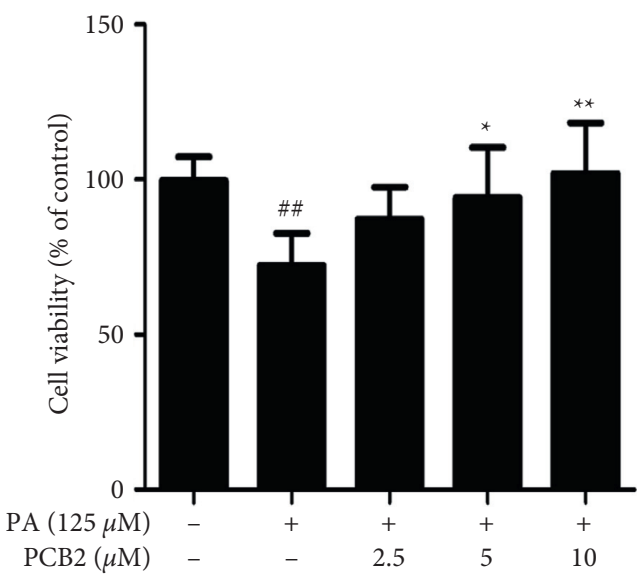

(d)

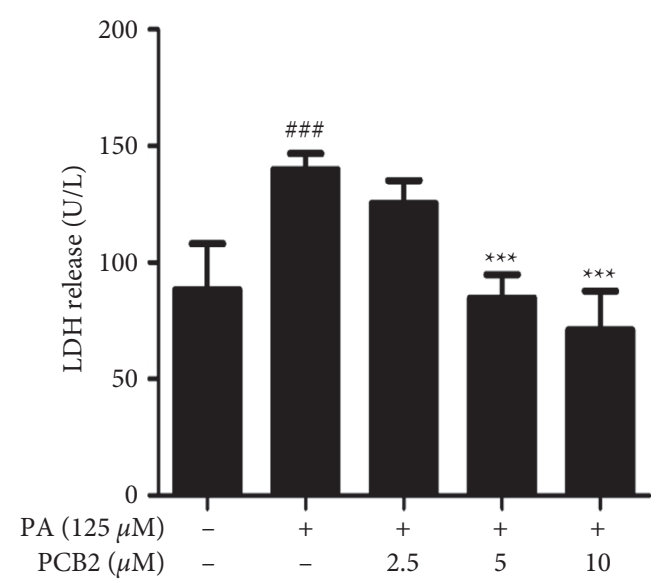

(e)

FIGURE 1: PCB2 protects HepG2 cells from PA-induced cell injury. (a) The chemical structure of PCB2. (b) HepG2 cells were treated with various concentrations of palmitic acid (from 50 to $250 \mu \mathrm{M}$ ) for 8,16 , and $24 \mathrm{~h}$ respectively. Cell viability was measured using CCK- 8 and normalized to control (\%). (c) Cytotoxicity of PCB2 (from 2.5 to $100 \mu \mathrm{M}$ ) for $24 \mathrm{~h}$. (d) HepG2 cells were exposed to PA (125 $\mu \mathrm{M}$ ) and treated by PCB2 $(2.5,5$, and $10 \mu \mathrm{M})$ for $24 \mathrm{~h}$. (c) HepG2 cells were treated as in (d), and (e) LDH released in the supernatant of cells was measured with a detection kit. The data are presented as means \pm S.D. ${ }^{\# \#} P<0.01$ and ${ }^{\# \# \#} P<0.001$ vs control, ${ }^{*} P<0.05$, ${ }^{* *} P<0.01$, and ${ }^{* * *} P<0.001$ vs model group. 
2.5. Cell Viability. Cell viability was determined using the Cell Counting Kit-8. Briefly, cells were seeded in 96-well plates (5000 cells/well) for $24 \mathrm{~h}$. Then, the supernatant was replaced by culture medium containing various concentrations of PCB2 (with or without PA) and the plates were put back to the incubator for another $24 \mathrm{~h}$. Next, the supernatant was replaced by CCK- 8 solution $(10 \mu \mathrm{L}$ CCK- 8 in $90 \mu \mathrm{L}$ DMEM per well) and incubated for $2 \mathrm{~h}$. The optical density (OD) values were measured at $450 \mathrm{~nm}$ using a microplate reader (Thermo Fisher Scientific, MA, USA). Cell viability $(\%)=(\mathrm{OD}$ (treatment) $-\mathrm{OD}$ (blank) $) /(\mathrm{OD}$ (control) - OD (blank) $) \times 100 \%$.

2.6. LDH Release. HepG2 cells were exposed to PCB2 with or without PA as above. Then, a commercial kit was used for the detection of LDH release from the cells, according to the manufacturer's instructions. Absorbance was measured at $450 \mathrm{~nm}$. LDH $(\mathrm{U} / \mathrm{L})=(\mathrm{OD}$ (treatment) $-\mathrm{OD}$ (blank) $) /(\mathrm{OD}$ (standard) - OD (blank) $) \times 0.2(\mathrm{mmol} / \mathrm{L}) \times 1000$.

2.7. Annexin V/PI Staining. HepG2 cells were treated as shown previously after $12 \mathrm{~h}$ incubation in 6-well plates with an initial density of $2 \times 10^{5}$ cells per well. All the operations simply followed the instructions. First, cells were harvested with the corresponding supernatants. Then, cells were washed twice with cold phosphate-buffered saline (PBS, Gibco) after centrifugation (500×g, $5 \mathrm{~min}$ ). Next, cells were suspended in binding buffer, stained with Annexin V-FITC and PI for $5 \mathrm{~min}$ at room temperature, and detected within an hour with BD FACSCelesta (BD Biosciences, NJ, USA), and data were analyzed using FlowJo Software (BD, version: 10.7.2).

2.8. TUNEL Staining. According to the instructions of the One-step TUNEL Apoptosis Assay Kit, cells were grown on cover glasses (NEST, Wuxi, Jiangsu Province, China) placed at the bottom of a 24 -well plate $\left(3 \times 10^{4}\right.$ cells/well $)$ and exposed to PA with or without PCB2 as described. The supernatant was removed, fixed by $4 \%$ paraformaldehyde for $30 \mathrm{~min}$, permeabilized for $5 \mathrm{~min}$ with PBS containing $0.3 \%$ Triton X-100, and incubated with TUNEL working solution (mixed $5 \mu \mathrm{L}$ terminal deoxynucleotidyl transferase and $45 \mu \mathrm{L}$ fluorescent labeling solution for each sample) in the dark for $60 \mathrm{~min}$ at $37^{\circ} \mathrm{C}$. The cover glasses were washed 3 times and then stained with DAPI solution $(0.5 \mu \mathrm{g} / \mathrm{mL}$ in PBS) for $1 \mathrm{~min}$. The cover glasses were washed once more and placed in drying oven until desiccated. Images were captured using a fluorescence microscope (Olympus, Tokyo, Japan), and the relative intensity of fluorescence was measured using ImagePro Plus Software (Media Cybernetics, Inc., MD, USA, version: 6.0).

2.9. Intracellular Reactive Oxygen Species (ROS) Detection. We used a fluorescent probe-DCFH-DA-to monitor intracellular ROS of HepG2 cells induced by PA. Cells were cultured as mentioned in the TUNEL staining assay except for the use of cover glasses, and the drug exposure duration was shortened to 12 hours. DCFH-DA was diluted in the culture medium as the final concentration was reduced to $10 \mu \mathrm{M}$, with a $30 \mathrm{~min}$ incubation in the incubator. Then, gentle wash by PBS and re-incubation by DMEM are needed since it is essential to make the background clear. Observation of the highlighted green fluorescence was performed on the fluorescence microscope (Olympus).

2.10. Intracellular SOD/MDA/Ca ${ }^{2+}$ Detection. HepG2 cells were grown in $100 \mathrm{~mm}$ dishes and treated for $24 \mathrm{~h}$. Cells were suspended in cold PBS and ruptured by ultrasonic instrument (Shunma Tech, Jiangsu Province, China) at a low power. Thus we acquired limpid supernatant and then determined protein concentrations with a Bicinchoninic Acid (BCA) Assay Kit (TransGen Biotech, Beijing, China) and used detection kit of SOD for evaluation. MDA and $\mathrm{Ca}^{2+}$ levels were measured in the same way. Operations were followed by the instructions of the kits. For SOD detection, after the determination of protein contents we need to dilute the supernatant to a proper concentration, making SOD inhibitory rate vary around $40 \%-60 \%$.

The SOD inhibitory rate $(\%)=\{(\mathrm{OD}$ (control) $-\mathrm{OD}$ (control blank) - (OD (treatment) - OD (treatment blank))\}/(OD (control) - OD (control blank)) $\times 100 \%$.

The SOD activity $(\mathrm{U} / \mathrm{mg})=$ SOD inhibitory rate $/ 50 \% \times$ (reactive system $(\mu \mathrm{l}) /($ dilute proportion))/protein contents $(\mathrm{mg} / \mathrm{mL})$.

The MDA contents $(\mathrm{nmol} / \mathrm{mg})=(\mathrm{OD}$ (treatment $)-\mathrm{OD}$ (blank))/(OD (standard) - OD (blank)) $\times$ MDA standard $(10 \mathrm{nmol} / \mathrm{ml}) /$ protein contents $(\mathrm{mg} / \mathrm{mL})$.

The calcium contents $(\mu \mathrm{mol} / \mathrm{mg})=(\mathrm{OD}$ (treatment $)$ - OD (blank))/(OD (standard) - OD (blank)) $\times$ calcium standard $(10 \mathrm{nmol} / \mathrm{ml}) /$ protein contents $(\mathrm{mg} / \mathrm{mL})$.

2.11. ER-Tracker Red and Hoechst 33342 Staining. HepG2 cells were treated as in the ROS detection assay. $5 \mu \mathrm{L}$ ERTracker Red was mixed with $10,000 \mu \mathrm{L}$ ER-Tracker Red diluent preheated in the $37^{\circ} \mathrm{C}$ water bath. Then, a total of $10,005 \mu \mathrm{L}$ working solution took the place of culture medium and incubated at $37^{\circ} \mathrm{C}$ in the dark for $30 \mathrm{~min}$. Next, each well was washed by PBS, followed by Hoechst 33342 $(1 \mu \mathrm{g} / \mathrm{ml}$ in PBS) staining for $1 \mathrm{~min}$. The cells were observed using a fluorescence microscope under excitation wavelength of $587 \mathrm{~nm} /$ emission wavelength of $615 \mathrm{~nm}$ for ERTracker Red staining and excitation wavelength of $346 \mathrm{~nm} /$ emission wavelength of $460 \mathrm{~nm}$ for Hoechst 33342 staining.

2.12. Quantitative Real-Time Polymerase Chain Reaction (PCR) Analysis. HepG2 cells were cultured in $60 \mathrm{~mm}$ dishes with $1 \times 10^{6}$ cells per vessel and exposed to drugs for $8 \mathrm{~h}$. RNA was extracted from cells using RNA Easy Fast Tissue/ Cell Kit (Tiangen Biotech, Beijing, China). The RNA concentration from each sample was measured using NanoDrop 2000 (Thermo Fisher Scientific). Samples with a concentration of $200-500 \mathrm{ng} / \mu \mathrm{L}$ and an $\mathrm{OD}_{260 / 280}$ value of $2.0-2.5$ were used in subsequent experiments. A total of $1.5 \mu \mathrm{g}$ RNA from each sample was used for reverse transcription and 
cDNA synthesis with FastKing gDNA Dispelling RT SuperMix (Tiangen Biotech). The real-time PCR $(20 \mu \mathrm{L})$, containing $10 \mu \mathrm{L} 2 \times$ Talent qPCR PreMix, $0.3 \mu \mathrm{L}$ primers (forward and reverse, respectively, $20 \mu \mathrm{mol} / \mathrm{L}$ ), $1.0 \mu \mathrm{L}$ cDNA template, $0.4 \mu \mathrm{L}$ ROX Dye $(50 \times)$, and $8.0 \mu \mathrm{L}$ RNase-free $\mathrm{ddH}_{2} \mathrm{O}$, was performed on ABI 7500 System (Applied Biosystems, MA, USA). The PCR amplification procedures were set as manual states: predenaturation at $95^{\circ} \mathrm{C}$ for $3 \mathrm{~min}$ followed by 40 cycles at $95^{\circ} \mathrm{C}$ for $5 \mathrm{~s}$ and $60^{\circ} \mathrm{C}$ for $32 \mathrm{~s}$. The mRNA levels were normalized to $\beta$-actin and assessed using the $2^{-\Delta \Delta \mathrm{Ct}}$ method. The primer sequences for genes of interest are listed in Table 1.

2.13. Western Blotting. At the end of the drug intervention, HepG2 cells were vortexed in cold RIPA buffer with protease and phosphatase inhibitor for $10 \mathrm{~min}$. Total proteins were extracted after centrifugation (14000 rpm, $\left.10 \mathrm{~min}, 4^{\circ} \mathrm{C}\right)$, and protein concentrations were determined using a BCA Assay Kit (TransGen Biotech). Protein samples from each group were subjected to an SDS-PAGE system and transferred to polyvinylidene fluoride (PVDF) membranes (Millipore, Billerica, MA, USA). The membranes were blocked by $5 \%$ (w/v) skim milk at room temperature for $60 \mathrm{~min}$, then washed 3 times with Tris-buffered saline containing $0.1 \%$ Tween-20 (TBST), and incubated with primary antibody at $4^{\circ} \mathrm{C}$ overnight with slight shaking. The membranes were washed 3 times and incubated with secondary antibody at room temperature for $2 \mathrm{~h}$. Finally, the membranes were washed another 3 times and exposed to Immobilon Western Chemiluminescent HRP Substrate (Millipore). Protein bands were gauged with ChemiDoc Imaging Systems (BioRad, CA, USA).

2.14. Statistical Analysis. All experiments were performed at least three times with triplicate using a one-way analysis of variance. Statistical analyses were performed using GraphPad Prism Software (GraphPad Software; San Diego, CA, USA, version: 8.0). The data were expressed as mean$s \pm$ standard deviation (S.D.). Comparisons between different groups were carried out with Student's $t$-test as appropriate. A value of $P<0.05$ was considered to be significant.

\section{Results}

3.1. PCB2 Protects HepG2 Cells from PA-Induced Cell Injury. Previous studies have shown that PA causes damage to HepG2 cells, so we tried to establish the PA-induced injured HepG2 model in a concentration- and time-dependent manner. Cell viability of the groups exposed to PA decreased gradually with concentration increased. For 8h-treated groups, there was no significance v.s. control. The cell viability of 16 h-treated groups was all above $80 \%$, and that of $24 \mathrm{~h}$-treated groups decreased further to $60 \%-70 \%$ importantly, cell viability of $125 \mu \mathrm{M}$ PA was $66.48 \pm 4.9 \%$ $(P<0.001$ vs control, Figure 1(b)). The data in Figure 1(c) showed that intervention of PCB2 from 2.5 to $100 \mu \mathrm{M}$ led to decrease in cell viability in a concentration-dependent manner, and when it is below $20 \mu \mathrm{M}$ of PCB2, there was no significance vs control. Next, we used CCK-8, a modified method of MTT assay, to assess the protective effect of PCB2 against PA. The data showed that PA $(125 \mu \mathrm{M})$ caused significant cell damage (cell viability decreased to $72.55 \pm 9.3 \%, P<0.01$ vs control), whereas PCB2 $(2.5,5$, and $10 \mu \mathrm{M})$ reversed the damage in a concentration-dependent manner, with cell viability rising to $102.28 \pm 15.0 \%$ in the high concentration group $(P<0.01$ vs model, Figure $1(\mathrm{~d}))$. Furthermore, we detected LDH release from injured cells to assess cytotoxicity following drug exposure. As shown in Figure 1(e), LDH released from model cells was dramatically inflated to $139.93 \pm 6.15 \mathrm{U} / \mathrm{L}(P<0.001$ vs control), whereas PCB2 (5 and $10 \mu \mathrm{M}$ ) significantly scaled down the release and remedied the cytotoxicity $(84.82 \pm 9.0$ and $71.13 \pm 15.16 \mathrm{U} / \mathrm{L}$, respectively, $P<0.001$ vs model). Briefly, our results indicate that $\mathrm{PCB} 2$ is well protected against PAinduced damage to HepG2 cells.

3.2. PCB2 Inhibits Apoptosis in PA-Stressed HepG2 Cells. To determine the apoptosis in HepG2 cells accurately, quantitative assays were performed on a flow cytometer using Annexin V/PI staining. Translocation of phosphatidylserine occurred in early apoptotic cells whose cytomembranes were stained with Annexin V only. Late apoptotic cells had incomplete cell membranes, resulting in nuclei stained with PI. Cells stained by both Annexin V and PI were considered necrotic or fragmented. Dot plots (Figure 2(a)) showed percentage of apoptotic cells (early and late apoptotic cells) in each group-it was $2.19 \%$ in control, $45.38 \%$ in model $(P<0.001$ vs control $), 39.29 \%$ in low concentration (n.s.), $20.33 \%$ in medium concentration $(P<0.001$ vs model $)$, and $14.6 \%$ in high concentration $(P<0.001$ vs model), respectively. Moreover, to observe apoptosis directly, TUNEL staining was performed on HepG2 cells. This was based on the ability of TdT to catalyze the addition of dUTPs labeled with Cy3 to free 3 '-hydroxyl termini of DNA, thereby enabling visualization of nuclei containing fragmented DNA cleaved in the biological process of apoptosis. Images of red (TUNEL) and blue (DAPI) fluorescence were captured (Figure 2(b)), and the relative intensity of the fluorescence was measured. The model group had more red apoptotic cells with higher relative fluorescence intensity than the control group $(P<0.001)$, which was significantly prevented by PCB2 treatment. These results are in line with flow cytometry analysis, suggesting that PCB2 can effectively mitigate apoptosis in PA-stressed HepG2 cells.

3.3. PCB2 Mitigates Oxidative Stress and Calcium Disequilibrium in PA-Induced HepG2 Cells. To assess the antioxidation effect of PCB2, indicators associated with oxidative stress, including ROS, MDA, and SOD, were measured. First, a cell-permeable fluorescent probe-DCFH-DA, blazes upon oxidation and can therefore be of great use in the sensitive and rapid quantitation of intracellular ROS. As shown in Figure 3, the more the ROS formation, the more prominent the captured green 
TAble 1: Primer sequences used in quantitative real-time PCR.

\begin{tabular}{lcc}
\hline Gene & Forward $\left(5^{\prime}-3^{\prime}\right)$ & Reverse $\left(5^{\prime}-3^{\prime}\right)$ \\
\hline Bax & GTTTTCTGACGGCAACTTCAACT & CCCATGATGGTTCTGATCAGTTC \\
$B$ - -2 & GTGTTCCGCGTGATTGAAGAC & TCCCAGAGGAAAAGCAACG \\
$\beta$-Actin & TCAAGATCATTGCTCCTCCTGAG & ACATCTGCTGGAAGGTGGACA \\
\hline
\end{tabular}

fluorescence, so PA (125 $\mu \mathrm{M})$-induced HepG2 cells were seen to be dramatically immersed in green and the relative fluorescence intensity elevated 10 times more than control $(P<0.001)$. After $12 \mathrm{~h}$ treatment of PCB2 $(2.5,5$, and $10 \mu \mathrm{M})$, the ROS were effectively reduced in a concentration-dependent manner $(P<0.01$ and $P<0.001$ vs model $)$. Likewise, MDA was assayed to examine lipid peroxidation and cell damage subjected to ROS attack, and as expected, much more MDA was formed in PA-stressed cells than in control cells $(P<0.01$, Table 2$)$ and showed a gradual decrease in PCB2-treated cells (evident in $10 \mu \mathrm{M}$ of PCB2, $P<0.01$ ), consistent with the intracellular ROS assay. We then measured SOD, one of the major antioxidant enzymes, whose activity controls the formation of ROS and therefore limits its potential toxicity and regulates broad aspects of cellular life. The data in Table 2 demonstrated that PCB2 restored the decrease in SOD activity induced by PA markedly $(P<0.01$ and $P<0.001$ vs model).

Calcium and redox homeostasis play key roles in cell life and death; therefore, we applied the tool of detection of $\mathrm{Ca}^{2+}$ in the cytoplasm. Also in Table 2, we observed a significant increase in cells exposed to PA $(P<0.001$ vs control $)$ and a decrease in cells treated with PCB2 $(P<0.01$ and $P<0.001$ vs model). Taken together, the evidence from these assays reveals that $\mathrm{PCB} 2$ has the ability to prevent oxidative stress and $\mathrm{Ca}^{2+}$ disequilibrium in PA-induced HepG2 cells.

3.4. PCB2 Rescues PA-Induced Endoplasmic Reticulum Dysfunction in HepG2 Cells. As the above results showed $\mathrm{Ca}^{2+}$ perturbations in the cells after treatment, we were increasingly interested in observing the damage to the ER caused by PA $(125 \mu \mathrm{M})$. We therefore assessed this with ERTracker Red, based on the ability of glibenclamide (glyburide) to bind specific receptors on ER, followed by Hoechst 33342 staining, which is cell-permeable, nucleispecific, and useful for studying apoptosis in live cells. The former glowed red fluorescence labeling ER, while the latter emitted blue labeling nuclei of apoptotic cells (Figure 4). The relevant mean fluorescence intensity was calculated for each group, and the results were consistent with the detection of $\mathrm{Ca}^{2+}$ level $(P<0.001)$.

3.5. PCB2 Performs Antiapoptosis Effect through Bcl-2 Family in PA-Induced HepG2 Cells. One of the vital regulators to apoptosis, known as the "Bcl-2 family," whose members (Bcl2, Bcl-XL, Mcl-1, etc.) prevent apoptosis, should be balanced with pro-apoptotic ones such as Bax, Bak, and Bad. Under certain stimuli, such as PA exposure as reported in numerous studies, it would lead to a boost in the $\mathrm{Bax} / \mathrm{Bcl}-2$ ratio and thus promote apoptosis. Herein, we determined the expressions of $\mathrm{Bcl}-2$ and $\mathrm{Bax}$ at both transcriptional and translational levels.
In PA $(125 \mu \mathrm{M})$-induced HepG2 cells, mRNA and protein expression of Bax (Figures 5(a) and 5(b)) was significantly increased compared with control $(P<0.001)$ and significantly decreased in PCB2 $(2.5,5$, and $10 \mu \mathrm{M})$-treated cells $(P<0.05$ and $P<0.01$ and $P<0.001$ vs model). As for $\mathrm{Bcl}-2$, the protein expression was significantly reduced in PA-exposed cells compared with control cells $(P<0.001)$ while exhibited a gradient elevation after PCB2 treatment (evident in 5 and $10 \mu \mathrm{M}$ of PCB2, $P<0.01$ and $P<0.001$ vs model). However, PCB2 treatment could not affect mRNA expression. All the above results suggest the antiapoptosis effect of PCB2 in HepG2 cells against PA is associated with Bcl-2 family.

3.6. PCB2 Alleviates Endoplasmic Reticulum Stress in PA-Induced HepG2 Cells. Furthermore, we applied Western blotting to assess PA $(125 \mu \mathrm{M})$-induced expression of target proteins associated with ERS in HepG2 cells. Upon PA stress, glucose-regulated proteins 78 (GRP78) and 94 (GRP94) dissociate and bind to misfolded or unfolded proteins, thus promoting phosphorylation of PERK, IRE1 $\alpha$, and the downstream eIF $\alpha$, leading to activation of CHOP, a key trigger for ERS-mediated apoptosis. The data in Figure 6(a) show that levels of both GRP78 and GRP94 were elevated in model cells $(P<0.001$ vs control $)$ and were restored by PCB2 $(P<0.01$ and $P<0.001$ vs model). In Figures 6(b) $-6(\mathrm{~d})$, the phosphorylation levels of PERK, eIF $2 \alpha$, and IRE1 $\alpha$ were upregulated by PA $(P<0.01$ and $P<0.001$ vs control $)$ and downregulated by PCB2 $(P<0.05$ and $P<0.01$ and $P<0.001$ vs model). In addition, $\mathrm{CHOP}$ expression was consistent with the above targets.

To determine the involvement of the protection of PCB2 to injured HepG2 cells induced by PA, 4-PBA, a compound that inhibits ER stress, was used to verify the protective effect. As shown in Figures 6(e) and 6(f), 4-PBA (2 mM) increased cell viability and decreased relative expression of crucial targets of ERS pathway-GRP78 and CHOP $(P<0.001$ vs model group). PCB2 treatment $(10 \mu \mathrm{M})$ was similar to the co-treatment of PA and 4-PBA (n.s.). Furthermore, TG, an ER stress agonist, led to significant cell death and overexpression of GRP78 and CHOP $(P<0.001$ vs control), as well as partly counteracted the hepatic protection of PCB2 when co-treated with it (n.s.). Overall, our data indicated that PCB2 mitigates endoplasmic reticulum stress in HepG 2 cells against PA exposure, and the protective effect is ERS pathway-dependent.

3.7. PCB2 Suppresses ERS-Mediated NLRP3 Inflammasome Activation in HepG2 Cells. There is growing evidence that ERS-induced activation of the NLRP3 inflammasome underlies the pathology of various inflammatory diseases. To investigate whether PCB2 affects these pathological 

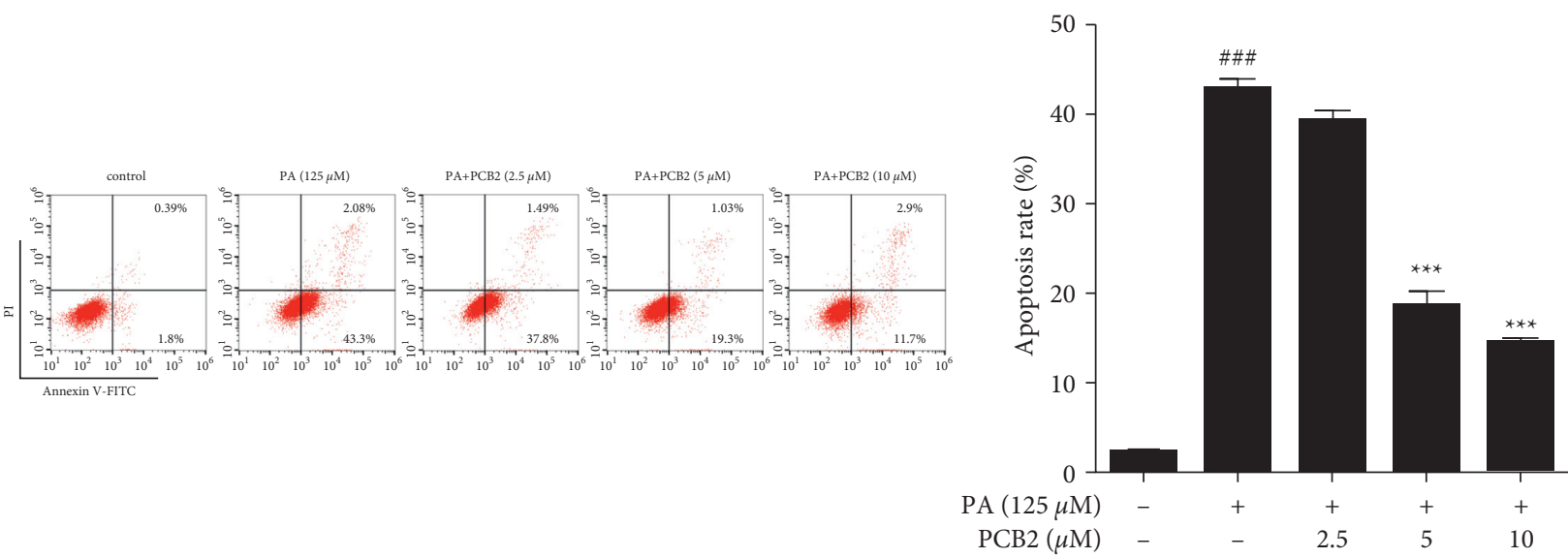

(a)

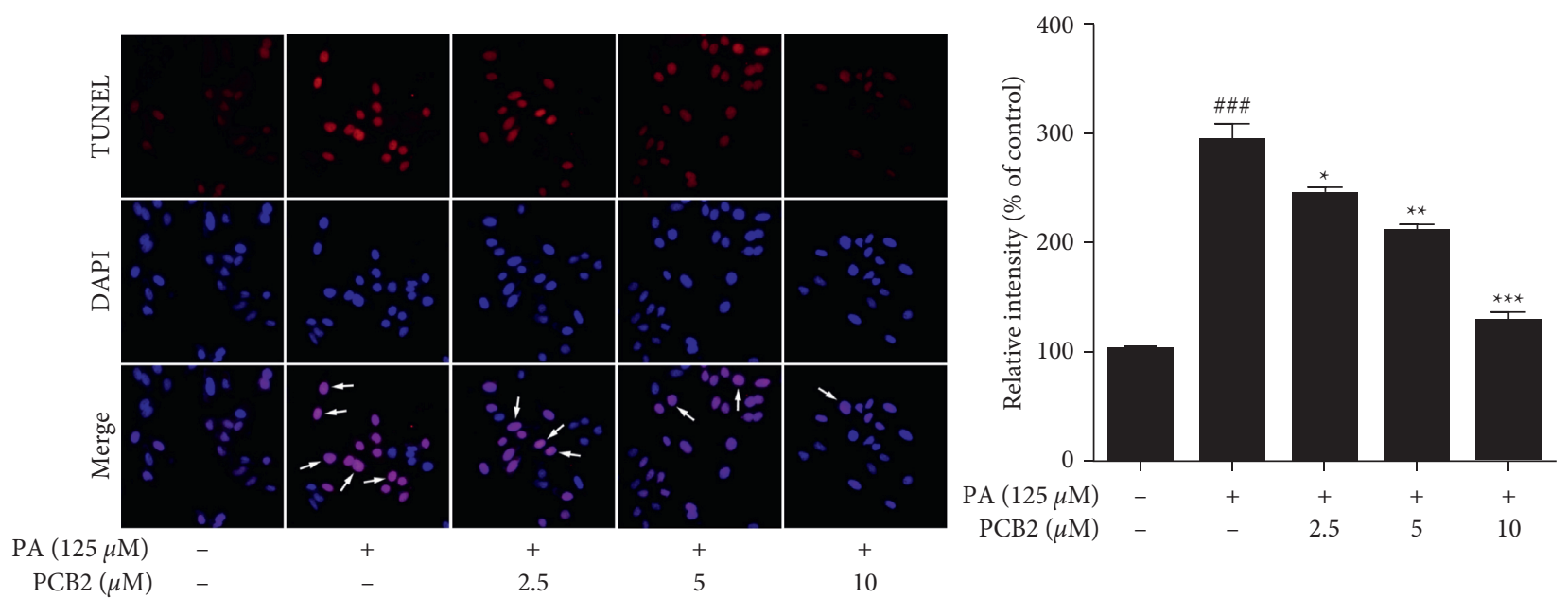

(b)

Figure 2: PCB2 inhibits apoptosis in PA-stressed HepG2 cells. (a) HepG2 cells were exposed to PA (125 $\mu$ M) and treated by PCB2 (2.5, 5, and $10 \mu \mathrm{M}$ ) for $12 \mathrm{~h}$. Apoptosis rate was determined with Annexin V-FITC/PI staining on a flow cytometer. (b) HepG2 cells were exposed to PA with or without PCB2 for $24 \mathrm{~h}$. Fixed cells were incubated with TUNEL (red) and DAPI (blue) solution, respectively, and relative fluorescence intensity was measured. Scale bar $=50 \mu \mathrm{m}$. Typical apoptotic cells were marked with white arrows. The data are presented as means \pm S.D. ${ }^{\# \# \#} P<0.001$ vs control, ${ }^{*} P<0.05,{ }^{* *} P<0.01$, and ${ }^{* * *} P<0.001$ vs model group.

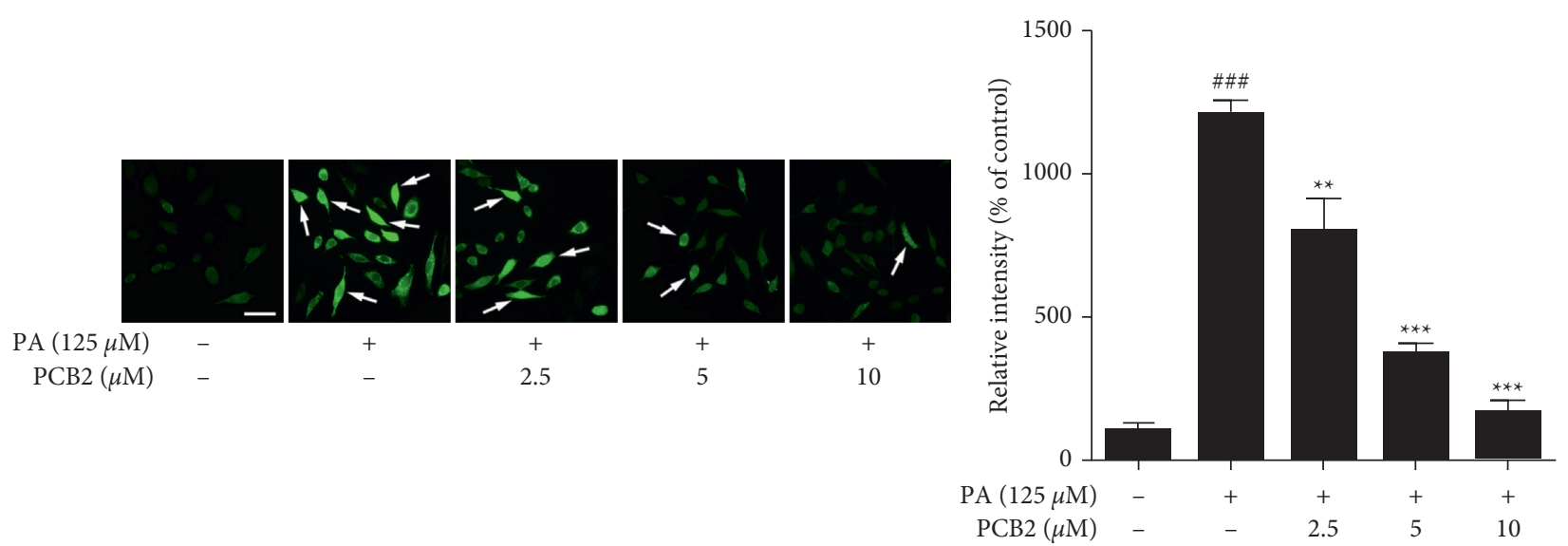

Figure 3: PCB2 inhibits ROS formation in PA-induced HepG2 cells. Cells were exposed to PA (125 $\mu \mathrm{M})$ and treated by PCB2 (2.5, 5, and $10 \mu \mathrm{M}$ ) for $12 \mathrm{~h}$. Intracellular ROS detected with DCFH-DA (green) and relative fluorescence intensity were measured. Scale bar $=50 \mu \mathrm{m}$. Typical cells with excessive ROS were marked by white arrows. The data are presented as means \pm S.D. ${ }^{\# \# \#} P<0.001$ vs control, ${ }^{* *} P<0.01$ and ${ }^{* * * *} P<0.001$ vs model group. 
TABle 2: Effect of PCB2 on SOD, MDA, and $\mathrm{Ca}^{2+}$ levels in PA-induced HepG2 cells

\begin{tabular}{|c|c|c|c|}
\hline Groups & SOD (U/mg) & MDA (nmol/mg) & $\mathrm{Ca}^{2+}(\mu \mathrm{mol} / \mathrm{mg})$ \\
\hline Control & $2980.011 \pm 140.288$ & $1.165 \pm 0.106$ & $0.181 \pm 0.01$ \\
\hline $\mathrm{PA}(125 \mu \mathrm{M})$ & $2405.464 \pm 90.575^{\# \#}$ & $1.521 \pm 0.032^{\# \#}$ & $0.224 \pm 0.004^{\# \# \#}$ \\
\hline $\mathrm{PA}+\mathrm{PCB} 2(2.5 \mu \mathrm{M})$ & $2953.916 \pm 105.401^{* *}$ & $1.347 \pm 0.024$ & $0.20 \pm 0.007^{* *}$ \\
\hline $\mathrm{PA}+\mathrm{PCB} 2(5 \mu \mathrm{M})$ & $3045.872 \pm 114.002^{* *}$ & $1.321 \pm 0.022$ & $0.196 \pm 0.009^{* * *}$ \\
\hline $\mathrm{PA}+\mathrm{PCB} 2(10 \mu \mathrm{M})$ & $3323.062 \pm 158.858^{* * *}$ & $1.193 \pm 0.038^{* *}$ & $0.19 \pm 0.008^{* * *}$ \\
\hline
\end{tabular}

HepG2 cells were exposed to PA $(125 \mu \mathrm{M})$ and treated by PCB2 $(2.5,5$, and $10 \mu \mathrm{M})$ for $24 \mathrm{~h}$. SOD, MDA, and Ca ${ }^{2+}$ levels were detected by kits, respectively. The bold values are presented as means \pm S.D. ${ }^{\# \#} P<0.01$ and ${ }^{\# \# \#} P<0.001$ vs control, ${ }^{*} P<0.05,{ }^{* *} P<0.01$, and ${ }^{* * *} P<0.001$ vs model groups For SOD level, control vs. PA: $P=0.0066$; PA vs. $2.5 \mu \mathrm{M}: P=0.0089$; PA vs. $5 \mu \mathrm{M}: P=0.0031$; PA vs. $10 \mu \mathrm{M}: P=0.0002$. For MDA level, control vs. PA: $P=0.0027$; PA vs. $10 \mu \mathrm{M}$ : $P=0.0053$. For $\mathrm{Ca}^{2+}$ level, control vs. $\mathrm{PA}: \mathrm{P}<0.0001$; PA vs. $2.5 \mu \mathrm{M}: P=0.0014$; $\mathrm{PA}$ vs. $5 \mu \mathrm{M}: P=0.0003$; $\mathrm{PA}$ vs. $10 \mu \mathrm{M}: \mathrm{P}<0.0001$.
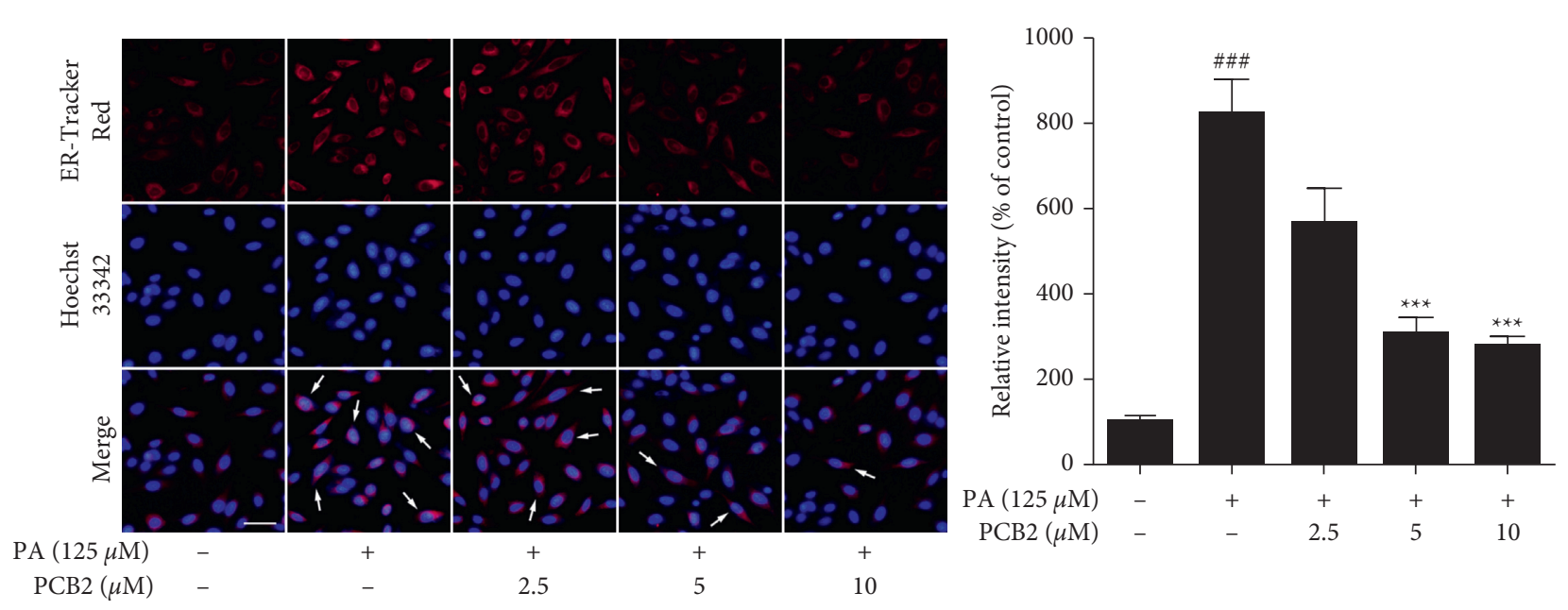

Figure 4: PCB2 rescues PA-induced endoplasmic reticulum dysfunction in HepG2 cells. Cells were exposed to PA (125 $\mu \mathrm{M})$ and treated by PCB2 $(2.5,5$, and $10 \mu \mathrm{M})$ for $12 \mathrm{~h}$ and then incubated with ER-Tracker Red (red) and Hoechst 33342 (blue) solution, respectively, and relative fluorescence intensity was measured. Scale bar $=50 \mu \mathrm{m}$. Typical cells were marked with white arrows. The data are presented as means \pm S.D. ${ }^{\# \# \#} P<0.001$ vs control, ${ }^{* * *} P<0.001$ vs model group.

changes in HepG2 cells at the presence of ERS, we measured the relative expression of NLRP3, caspase 1, IL$1 \beta$, and components of the nuclear factor kappa $\mathrm{B}(\mathrm{NF}-\kappa \mathrm{B})$ pathway. The results in Figure 7 showed that PA $(125 \mu \mathrm{M})$ resulted in substantial upregulation of $\mathrm{p}-\mathrm{IKK} \alpha / \beta, \mathrm{p}-\mathrm{NF}-\kappa \mathrm{B}$ p65, NLRP3, cleaved caspase 1 , and cleaved IL- $1 \beta$ levels compared with control $(P<0.001)$, while PCB2 contributed to concentration-dependent inhibition $(P<0.01$ and $P<0.001$ vs model). Collectively, PCB2 could restrain ERS-mediated NLRP3 inflammasome activation and inflammation in PA-induced HepG2 cells.

\section{Discussion}

Nonalcoholic fatty liver disease (NAFLD) is the most prevalent chronic liver disease worldwide and is considered the hepatic manifestation of the metabolic syndrome associated with obesity and type 2 diabetes [4], increasing the risk of cardiovascular disease and some types of cancer. NAFLD is characterized by the accumulation of ectopic lipids in hepatocytes [1], during which the elevated circulating FFA derived from adipose tissue is required. Increased influx of FFA to the liver leads to lipotoxicity promoting progressive NAFLD $[9,12]$.
To a certain extent, traditional Chinese medicine (TCM) has a wealth of experience and effectiveness in the treatment of NAFLD. In China, TCM is used in decoctions to treat patients with various symptoms [28], but uncertainty about their mechanisms and inconsistent efficacy in large-scale randomized controlled trials limit the application of decoctions. Notably, there has been progress in a large number of basic studies on extracts or active ingredients of single herbs, with silymarin and berberine already in phase 4 clinical studies approved by the US Food and Drug Administration [29]. Similar researches are in full swing for providing effective drugs on NAFLD. As an active ingredient extracted from traditional Chinese herbal Cinnamon (Cinnamomum cassia) [24], PCB2 offers excellent hepatic protection, but few pharmacodynamic studies are reported to date.

PA has been shown to be the most common circulating saturated fatty acid that causes hepatocyte apoptosis and is associated with ERS. Recent studies have revealed that ERS is a contributor to the development of NAFLD [1]. In response to PA stimulation, excessive unfolded or misfolded proteins overloaded in ER induce excessive ROS formation and $\mathrm{Ca}^{2+}$ disequilibrium, thus activating ERS pathways. $\mathrm{Ca}^{2+}$ massive influx to mitochondrion leads to more ROS production in 

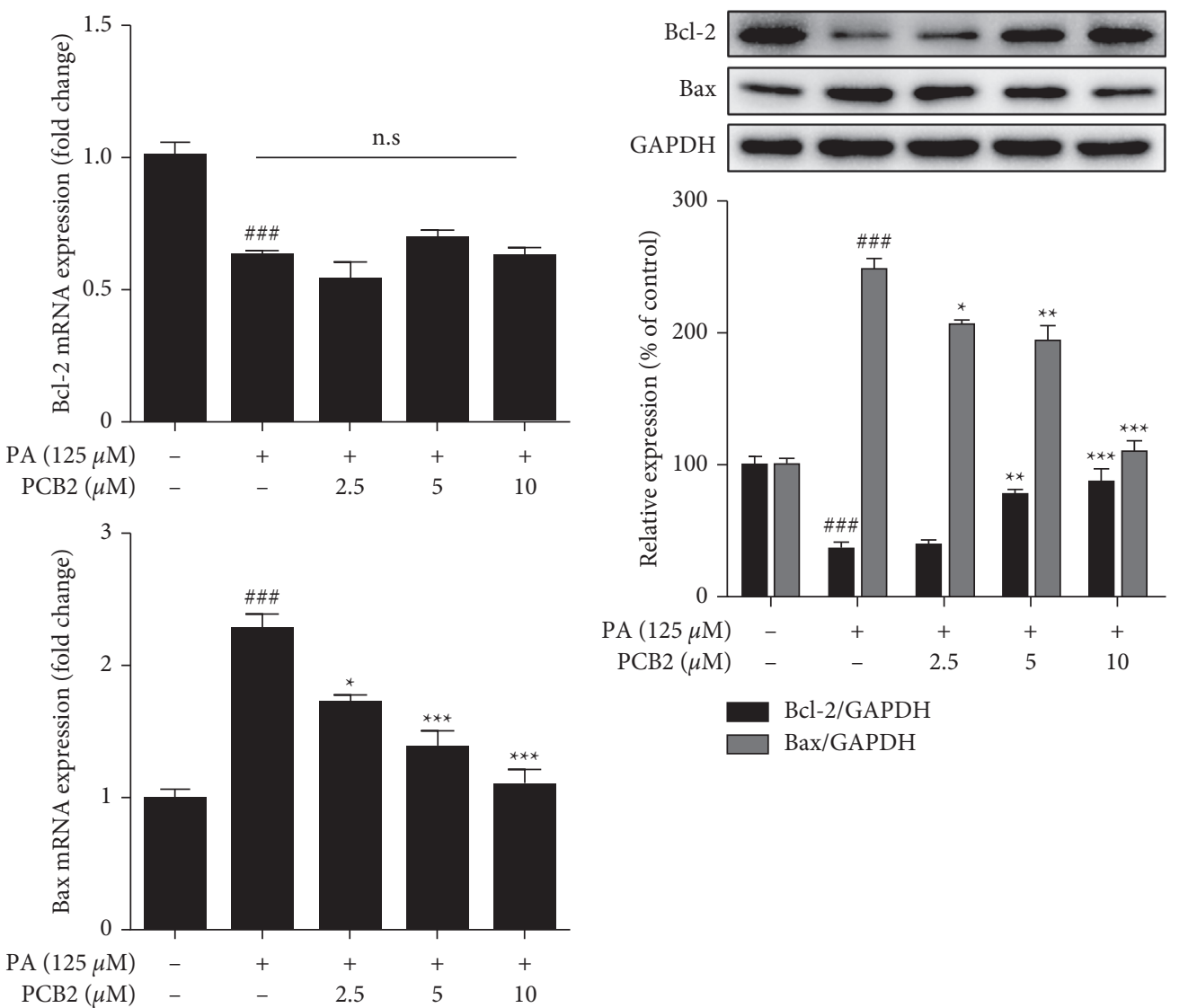

(a)

(b)

Figure 5: PCB2 performs anti-apoptosis effect through Bcl-2 family in PA-induced HepG2 cells. (a) HepG2 cells were exposed to PA $(125 \mu \mathrm{M})$ and treated by PCB2 $(2.5,5$ and $10 \mu \mathrm{M})$ for $8 \mathrm{~h}$. The mRNA levels of Bcl-2 and Bax were examined by qPCR. (b) HepG2 cells were exposed to drugs for $24 \mathrm{~h}$. The protein levels of Bcl-2 and Bax were examined by western blotting. Data are presented as mean \pm S.D. ${ }^{\# \# \#} P<0.001$ vs control, ${ }^{*} P<0.05,{ }^{* *} P<0.01$, and ${ }^{* * *} P<0.001$ vs model group.

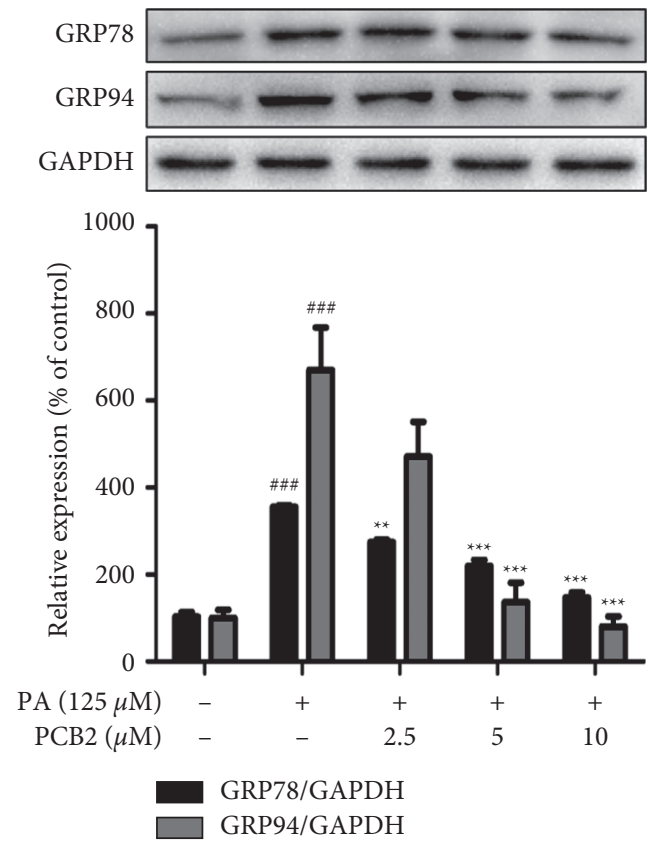

(a)
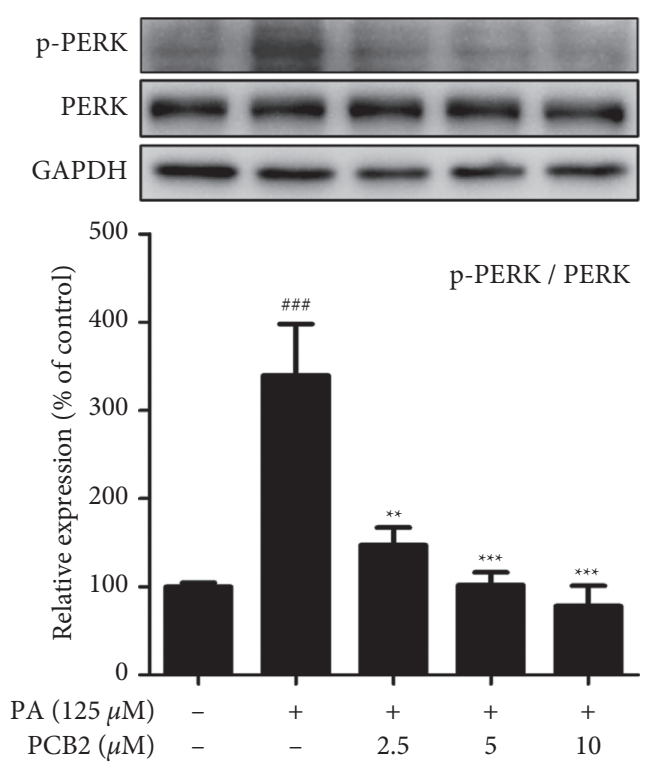

Figure 6: Continued.

(b) 

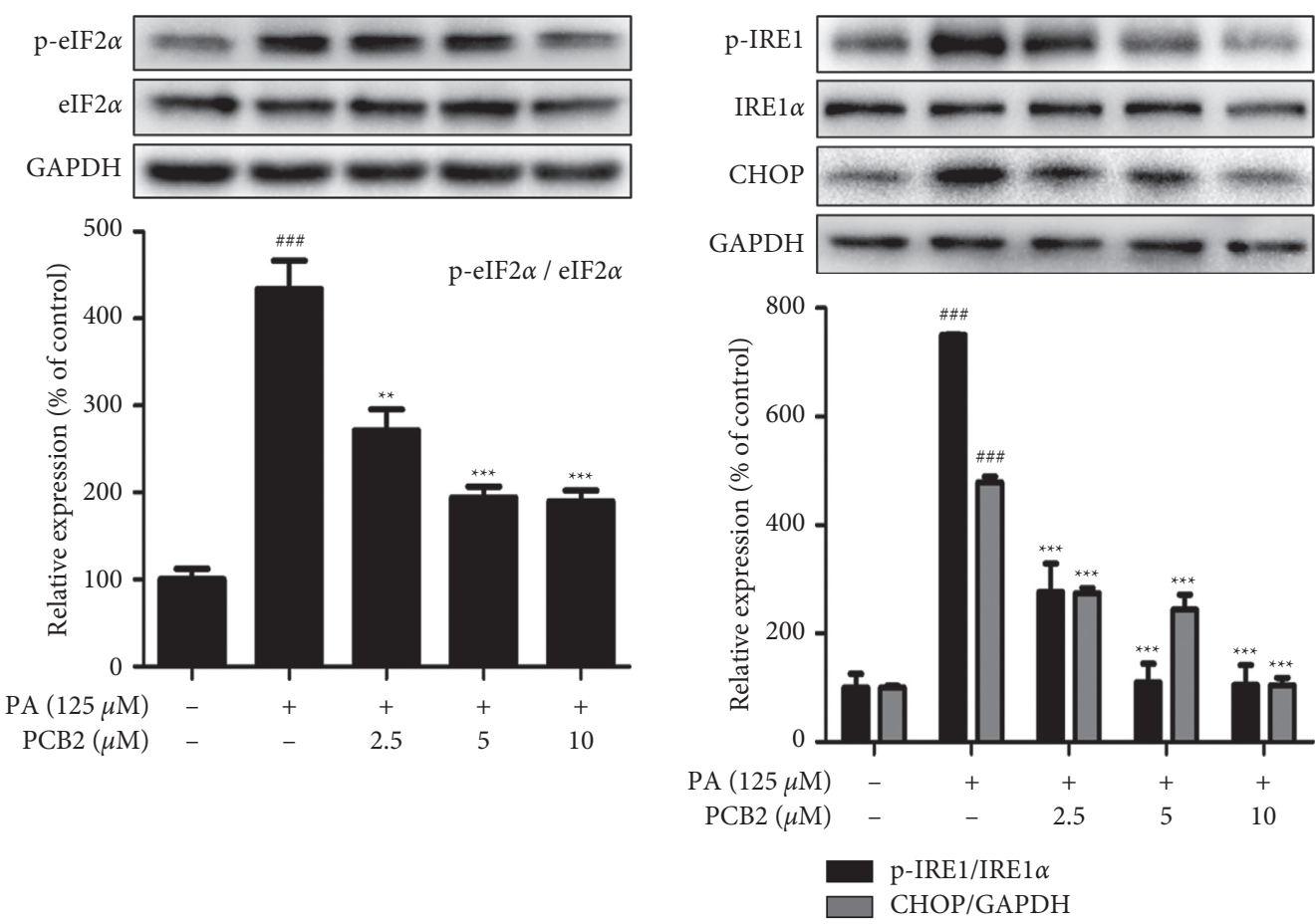

(c)

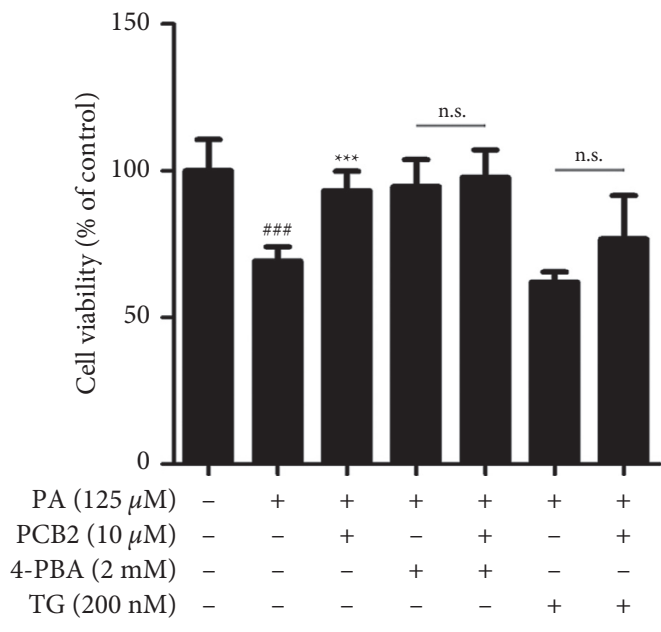

(e)

(d)
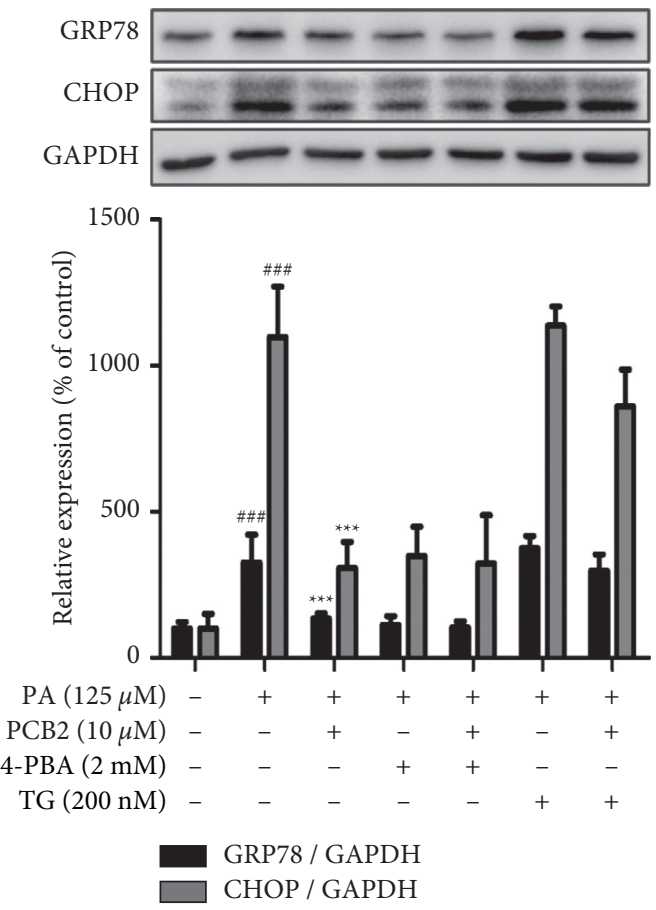

(f)

FIgUre 6: PCB2 alleviates endoplasmic reticulum stress in PA-induced HepG2 cells. Cells were exposed to PA (125 $\mu \mathrm{M})$ and treated by PCB2 $(2.5,5$, and $10 \mu \mathrm{M})$ for $24 \mathrm{~h}$. The protein levels were examined by Western blotting. (a) The protein levels of GRP78 and GRP94. (b) The protein levels of p-PERK and PERK. (c) The protein levels of p-eIF2 $\alpha$ and eIF2 $\alpha$. (d) The protein levels of p-IRE1, IRE1 $\alpha$, and CHOP. (e) Cell viability of model, PCB2 $(10 \mu \mathrm{M})$, and ERS pathway inhibitor/agonist-related groups. (f) HepG2 cells were treated as in (e), and the relative protein levels of GRP78 and CHOP were measured by Western blot. ${ }^{\# \# \#} P<0.001$ vs control, ${ }^{* *} P<0.01$ and ${ }^{* * *} P<0.001$ vs model group.

turn [30, 31]. In this study, we found that PCB2 effectively inhibited cytosolic $\mathrm{Ca}^{2+}$ overload and ROS formation in PAtreated HepG2 cells, which is consistent with the previous study demonstrating that PCB2 inhibits FFA-induced oxidative stress via restoring mitochondrial membrane potential and scavenging ROS [25]. 


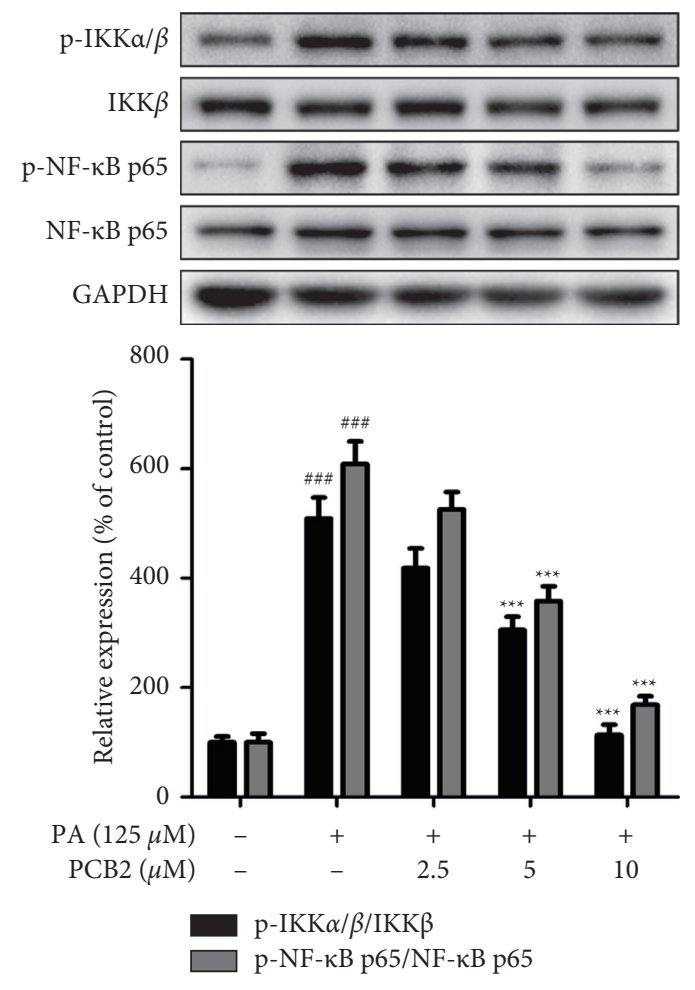

(a)

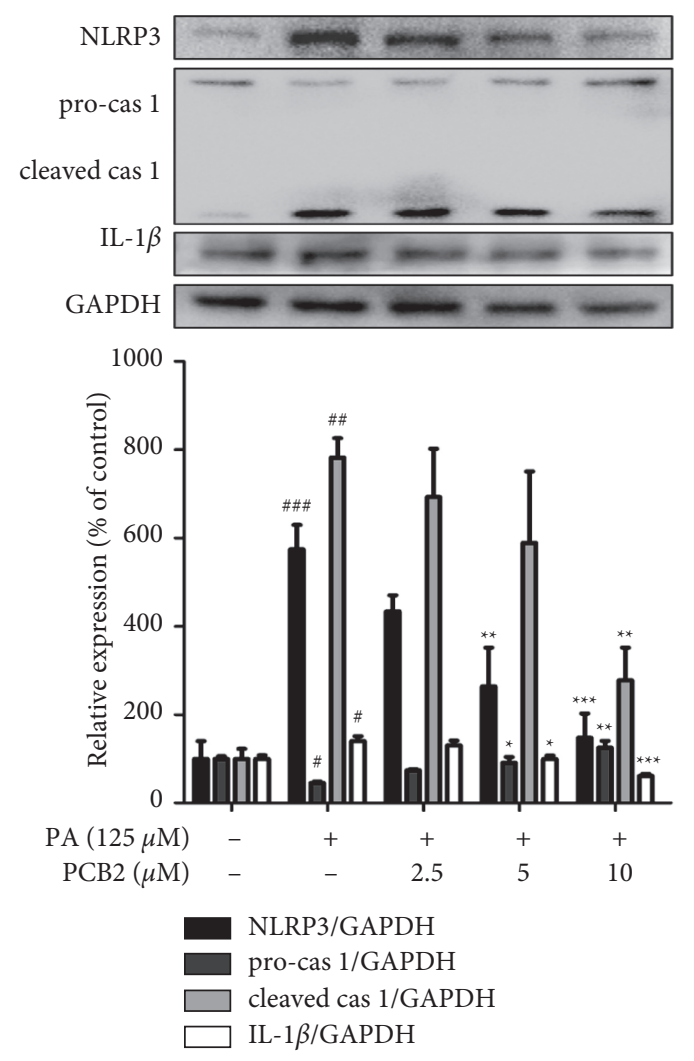

(b)

FIGURE 7: PCB2 suppresses ERS-mediated activation of NF- $\kappa$ B pathway and NLRP3 inflammasome in HepG2 cells. Cells were exposed to PA $(125 \mu \mathrm{M})$ and treated by PCB2 $(2.5,5$, and $10 \mu \mathrm{M})$ for $24 \mathrm{~h}$. The protein levels were examined by Western blotting. (a) The protein levels of $\mathrm{p}-\mathrm{IKK} \alpha / \beta, \mathrm{IKK} \beta$, p-NF- $\kappa \mathrm{B}$ p65, and NF- $\kappa \mathrm{B}$ p65. (b) The protein levels of NLRP3, pro-caspase 1, cleaved caspase 1 , and cleaved IL-1 $\beta$. ${ }^{\#} P<0.05,{ }^{\# \#} P<0.01$, and ${ }^{\# \#} P<0.001$ vs control, ${ }^{*} P<0.05,{ }^{* *} P<0.01$, and ${ }^{* * *} P<0.001$ vs model group.

In the physiological state, the transmembrane proteins of ER, PERK, and IRE1 $\alpha$ remain inactive and bind to the ER chaperone GRP78. As the bulk of unfolded proteins accumulate in ER, GRP78 dissociates from PERK- and IRE1 $\alpha$-activating downstream pathways, respectively, to reestablish cellular homeostasis. However, sustained or severe stimuli activate pro-apoptosis or inflammatory genes, resulting in irreversible cellular injury. At the same time, persistent UPR causes elevated protein expression of the ER chaperones GRP78 and GRP94 [32]. In this work, we observed that PCB2 downregulated the phosphorylation of PERK and IRE1 $\alpha$ as well as the protein levels of GRP78, GRP94, and CHOP, revealing that PCB2 attenuates extensive PA-induced ERS through molecular chaperones, stress sensors, and transcription factor levels, consequently rescuing cellular injury. Yogalakshmi et al. showed that PCB2 restrained ERS by downregulating mRNA levels of PERK, IRE $1 \alpha$, and ATF- 6 and protein levels of eIF $2 \alpha$ and XBP1 in high-calorie diet-fed rats [33]. Furthermore, we used 4-PBA and TG, the ER stress inhibitor and agonist, respectively $[34,35]$, to assess the protective role of $\mathrm{PCB} 2$ in the context of PA-induced injury in HepG2 cells, indicating that ERS-dependent prevention could be involved in its protective effects. Previous and current experiments have confirmed the anti-ERS effects of PCB2 at multiple levels.
ER stress is implicated in complicated signaling pathways. The literature reports that TXNIP, a natural antagonist of thioredoxin (TRX), is an important molecule linking ERS and cell apoptosis-upon ERS, phosphorylated PERK and IRE $1 \alpha$ activate thioredoxin-interacting protein (TXNIP) and NLRP3 inflammasome, which induce inflammation and cell death [36, 37]. The NLRP3 inflammasome is a multiprotein complex consisting of NLRP3, apoptosis-associated speck-like protein containing a CARD (ASC), and pro-caspase 1. Once the NLRP3 inflammasome activates, pro-caspase- 1 cleaves pro-IL- $1 \beta$ into a mature form, and thus, activated IL- $1 \beta$ triggers inflammation and cell injury via $\mathrm{NF}-\kappa \mathrm{B}$ pathway $[38,39]$. Our experiments revealed that PCB2 inhibits the activation of the NLRP3 inflammasome and the increase in the Bax/ $\mathrm{Bcl}-2$ ratio, which is a key regulator of the mitochondrial apoptosis pathway, in a concentration-dependent manner. Flow cytometry, TUNEL, and Hoechst 33342 staining proved the protective effect of PCB2 against apoptosis induced by PA in vitro. Previous studies have shown that ERS is a crucial mechanism in cell death driven by PA $[16,17]$; meanwhile, we did a preliminary but exploratory investigation of the effect of NLRP3 inflammasome activation regulated by $\mathrm{PCB} 2$ on ERS-mediated cell injury. $\mathrm{Li}$ Ma et al. reported that PCB2 significantly inhibited cold stimulation-induced NLRP3 inflammasome activation and 


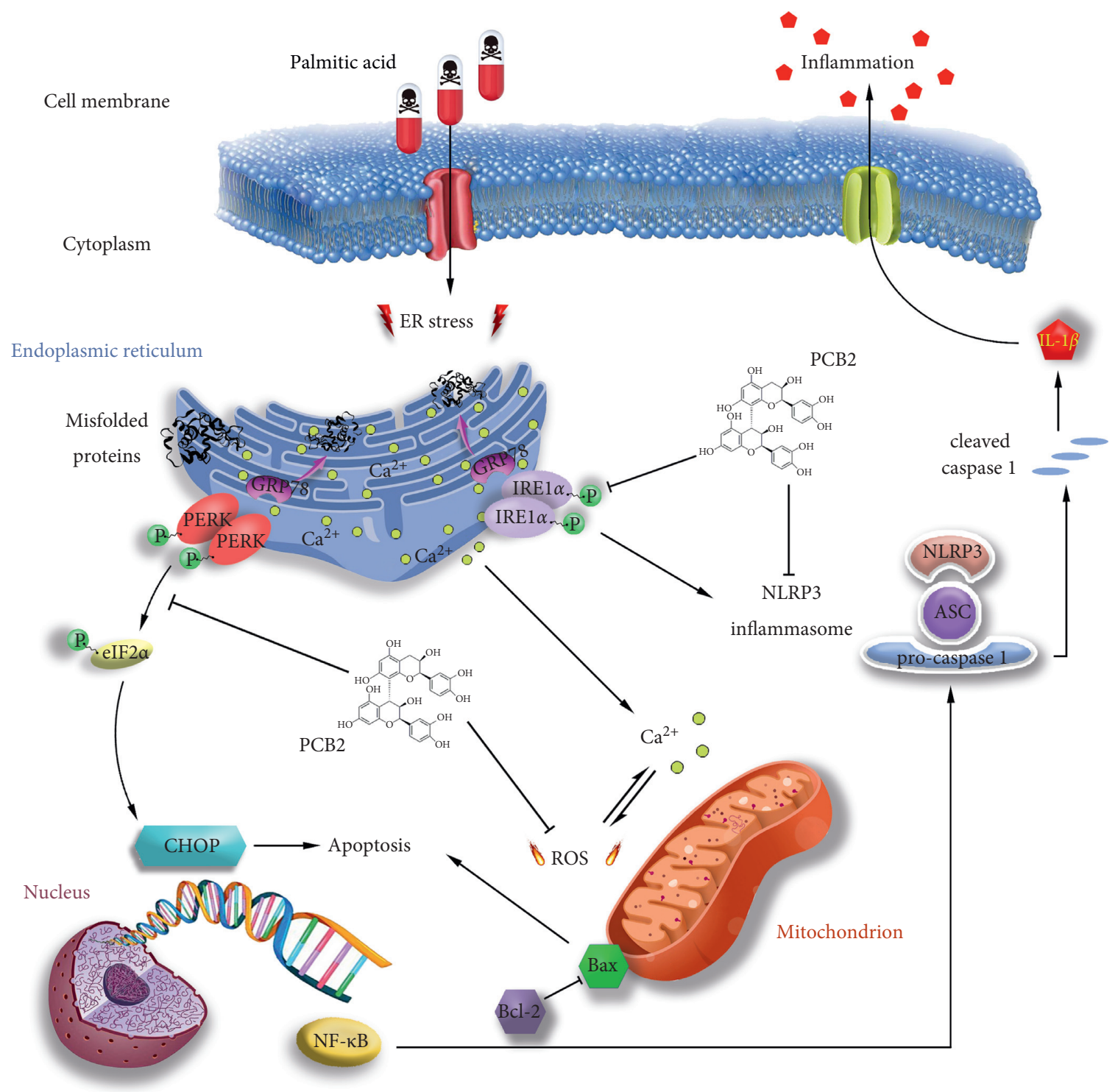

FIgURE 8: Mechanism of PCB2 against PA-induced injury in HepG2 cells.

IL-1 $\beta$ secretion in rats' liver [40]. Similarly, here we examined the protein expression of $\mathrm{p}-\mathrm{IKK} \alpha / \beta, \mathrm{p}-\mathrm{NF}-\kappa \mathrm{B}$ p 65 , NLRP3, cleaved caspase 1 , and mature IL- $1 \beta$, proving the inhibition of PCB2. Yet, it remains poorly understood that if PCB2 functions in vivo as above, we will perform experiments using rodent models for further investigations.

\section{Conclusions}

This work reveals the mechanism by which PCB2 attenuates PA-induced injury in HepG2 cells. PA results in NLRP3 inflammasome-dependent cellular inflammatory response and mitochondrial-dependent apoptosis at the presence of ROSmediated ERS. PCB2 intervention alleviates oxidative stress and endoplasmic reticulum stress while restoring antioxidant enzyme activities and $\mathrm{Ca}^{2+}$ equilibrium. Furthermore, PCB2 inhibits NF- $\kappa$ B and NLRP3/caspase $1 /$ IL- $1 \beta$ pathways associated with inflammation and $\mathrm{Bax} / \mathrm{Bcl}-2$-dependent cell apoptosis, thus promoting cell survival (Figure 8). All of these may provide preliminary pharmacological evidence for clinical treatment of NAFLD.

\section{Abbreviations}

NAFLD: Nonalcoholic fatty liver disease

NASH: Nonalcoholic steatohepatitis

FFA: $\quad$ Free fatty acids

PA: $\quad$ Palmitic acid

PCB2: Procyanidin B2

ER: $\quad$ Endoplasmic reticulum

ERS: $\quad$ Endoplasmic reticulum stress

UPR: Unfolded protein response

NLRP3: NOD-like receptor family pyrin domaincontaining 3

GRP78: $\quad$ Glucose-regulated protein 78

GRP94: Glucose-regulated protein 94 
PERK: Protein kinase RNA-like endoplasmic reticulum kinase

IRE1 $\alpha$ : Inositol-requiring enzyme $1 \alpha$

ATF6 $\alpha$ : Activating transcription factor $6 \alpha$

eIF2 $\alpha$ : $\quad$ Eukaryotic initiation factor $2 \alpha$

Bcl-2: B-cell lymphoma-2

Bax: $\quad$ Bcl-2-associated $\mathrm{X}$ protein

CHOP: $\quad \mathrm{C} / \mathrm{EBP}$ homologous protein

LDH: $\quad$ Lactate dehydrogenase

ROS: $\quad$ Reactive oxygen species

SOD: $\quad$ Superoxide dismutase

MDA: $\quad$ Malondialdehyde

TUNEL: Terminal deoxynucleotidyl transferase-mediated dUTP-biotin nick end-labeling

DAPI: $\quad 4^{\prime}, 6$-diamidino-2-phenylindole

DCFH- $\quad 2^{\prime}, 7^{\prime}$-Dichlorofluorescein diacetate

DA:

PCR: Polymerase chain reaction.

\section{Data Availability}

All data are available from the corresponding author upon request.

\section{Conflicts of Interest}

All authors declare no conflicts of interest.

\section{Authors' Contributions}

SM Li and BH Wang conceived and designed the experiments. YM Li and SY Zhao carried out the experiments and wrote the manuscript. YM Li and SY Zhao analyzed the data. $\mathrm{BH}$ Wang, SY Zhao, and $\mathrm{HH}$ Zhao contributed reagents/ materials/analysis tools. All authors have read and approved the manuscript. Yi-Ming Li and Shao-Yang Zhao contributed equally to this work and should be considered co-first authors.

\section{Acknowledgments}

The authors are grateful to the Lingnan Medical Research Center, Guangzhou University of Chinese Medicine, Guangzhou, Guangdong Province, China, for the assistance. This study was supported by the National Natural Science Foundation of China for Youth (Nos. 82104621 and 82104791) and Collaborative Innovation Team Construction Project of Guangzhou University of Chinese Medicine (No. 2021XK15).

\section{References}

[1] C. Lebeaupin, D. Vallée, Y. Hazari, C. Hetz, E. Chevet, and B. Bailly-Maitre, "Endoplasmic reticulum stress signalling and the pathogenesis of non-alcoholic fatty liver disease," Journal of Hepatology, vol. 69, no. 4, pp. 927-947, 2018.

[2] M. Eslam, A. J. Sanyal, J. George et al., "MAFLD: a consensusdriven proposed nomenclature for metabolic associated fatty liver disease," Gastroenterology, vol. 158, no. 7, pp. 1999-2014, 2020 .
[3] H. Malhi and R. J. Kaufman, "Endoplasmic reticulum stress in liver disease," Journal of Hepatology, vol. 54, no. 4, pp. 795-809, 2011.

[4] Z. M. Younossi, A. B. Koenig, D. Abdelatif, Y. Fazel, L. Henry, and M. Wymer, "Global epidemiology of nonalcoholic fatty liver disease-Meta-analytic assessment of prevalence, incidence, and outcomes," Hepatology, vol. 64, no. 1, pp. 73-84, 2016.

[5] H. Xu, Y. Tian, D. Tang et al., "An endoplasmic reticulum stress-micro RNA -26a feedback circuit in NAFLD," Hepatology, vol. 73, no. 4, pp. 1327-1345, 2021.

[6] A. Bayoumi, H. Grønbæk, J. George, and M. Eslam, "The epigenetic drug discovery landscape for metabolic-associated fatty liver disease," Trends in Genetics, vol. 36, no. 6, pp. 429-441, 2020.

[7] K. L. Donnelly, C. I. Smith, S. J. Schwarzenberg, J. Jessurun, M. D. Boldt, and E. J. Parks, "Sources of fatty acids stored in liver and secreted via lipoproteins in patients with nonalcoholic fatty liver disease," Journal of Clinical Investigation, vol. 115, no. 5, pp. 1343-1351, 2005.

[8] B. A. Neuschwander-Tetri, "Hepatic lipotoxicity and the pathogenesis of nonalcoholic steatohepatitis: the central role of nontriglyceride fatty acid metabolites," Hepatology, vol. 52, no. 2, pp. 774-788, 2010.

[9] S. Albhaisi and A. J. Sanyal, "Gene-environmental interactions as metabolic drivers of nonalcoholic steatohepatitis," Frontiers in Endocrinology, vol. 12, Article ID 665987, 2021.

[10] S. Francque, G. Szabo, M. F. Abdelmalek et al., "Nonalcoholic steatohepatitis: the role of peroxisome proliferator-activated receptors," Nature Reviews Gastroenterology \& Hepatology, vol. 18, no. 1, pp. 24-39, 2021.

[11] D. Ferguson and B. N. Finck, "Emerging therapeutic approaches for the treatment of NAFLD and type 2 diabetes mellitus," Nature Reviews Endocrinology, vol. 17, no. 8, pp. 484-495, 2021.

[12] F. Bessone, M. V. Razori, and M. G. Roma, "Molecular pathways of nonalcoholic fatty liver disease development and progression," Cellular and Molecular Life Sciences, vol. 76, no. 1, pp. 99-128, 2019.

[13] M. Ricchi, M. R. Odoardi, L. Carulli et al., "Differential effect of oleic and palmitic acid on lipid accumulation and apoptosis in cultured hepatocytes," Journal of Gastroenterology and Hepatology, vol. 24, no. 5, pp. 830-840, 2009.

[14] N. Ogino, K. Miyagawa, and K. Nagaoka, "Role of HO-1 against saturated fatty acid-induced oxidative stress in hepatocytes," Nutrients, vol. 13, no. 3, pp. 1-12, 2021.

[15] A. Alnahdi, A. John, and H. Raza, "Augmentation of glucotoxicity, oxidative stress, apoptosis and mitochondrial dysfunction in HepG2 cells by palmitic acid," Nutrients, vol. 11, no. 9, pp. 1-21, 2019.

[16] N. Ogino, K. Miyagawa, M. Kusanaga et al., "Involvement of sarco/endoplasmic reticulum calcium ATPase-mediated calcium flux in the protective effect of oleic acid against lipotoxicity in hepatocytes," Experimental Cell Research, vol. 385, no. 1, Article ID 111651, 2019.

[17] J. Zhang, H. Zhang, X. Deng, Y. Zhang, and K. Xu, "Baicalin protects AML-12 cells from lipotoxicity via the suppression of ER stress and TXNIP/NLRP3 inflammasome activation," Chemico-Biological Interactions, vol. 278, pp. 189-196, 2017.

[18] C.-X. Li, J.-G. Gao, X.-Y. Wan et al., "Allyl isothiocyanate ameliorates lipid accumulation and inflammation in nonalcoholic fatty liver disease via the Sirtl/AMPK and NF- $\kappa \mathrm{B}$ signaling pathways," World Journal of Gastroenterology, vol. 25, no. 34, pp. 5120-5133, 2019. 
[19] Y. Zou and M. Kong, "Tetrahydroxy stilbene glucoside alleviates palmitic acid-induced inflammation and apoptosis in cardiomyocytes by regulating miR-129-3p/Smad3 signaling," Cellular and Molecular Biology Letters, vol. 24, no. 5, pp. 5-14, 2019.

[20] Y. Wang, Q. Liu, Y. Huan et al., "Sirtuin 5 overexpression attenuates glucolipotoxicity-induced pancreatic $\beta$ cells apoptosis and dysfunction," Experimental Cell Research, vol. 371, no. 1, pp. 205-213, 2018.

[21] F. Marra and G. Svegliati-Baroni, "Lipotoxicity and the gutliver axis in NASH pathogenesis," Journal of Hepatology, vol. 68 , no. 2, pp. 280-295, 2018.

[22] W.-X. Zong, C. Li, G. Hatzivassiliou et al., "Bax and Bak can localize to the endoplasmic reticulum to initiate apoptosis," Journal of Cell Biology, vol. 162, no. 1, pp. 59-69, 2003.

[23] L. D. Ly, S. Xu, S.-K. Choi et al., "Oxidative stress and calcium dysregulation by palmitate in type 2 diabetes," Experimental \& Molecular Medicine, vol. 49, no. 2, p. e291, 2017.

[24] P. Sun, T. Wang, L. Chen et al., "Trimer procyanidin oligomers contribute to the protective effects of cinnamon extracts on pancreatic $\beta$-cells in vitro," Acta Pharmacologica Sinica, vol. 37, no. 8, pp. 1083-1090, 2016.

[25] H. Su, Y. Li, D. Hu et al., "Procyanidin B2 ameliorates free fatty acids-induced hepatic steatosis through regulating TFEB-mediated lysosomal pathway and redox state," Free Radical Biology and Medicine, vol. 126, pp. 269-286, 2018.

[26] J.-X. Liu, C. Yang, Z.-J. Liu et al., "Protection of procyanidin B2 on mitochondrial dynamics in sepsis associated acute kidney injury via promoting Nrf2 nuclear translocation," Aging, vol. 12, no. 15, pp. 15638-15655, 2020.

[27] B.-Y. Li, X.-L. Li, Q. Cai et al., "Induction of lactadherin mediates the apoptosis of endothelial cells in response to advanced glycation end products and protective effects of grape seed procyanidin B2 and resveratrol," Apoptosis, vol. 16, no. 7, pp. 732-745, 2011.

[28] K.-Q. Shi, Y.-C. Fan, W.-Y. Liu, L.-F. Li, Y.-P. Chen, and M.-H. Zheng, "Traditional Chinese medicines benefit to nonalcoholic fatty liver disease: a systematic review and metaanalysis," Molecular Biology Reports, vol. 39, no. 10, pp. 9715-9722, 2012.

[29] T. Yan, N. Yan, P. Wang et al., "Herbal drug discovery for the treatment of nonalcoholic fatty liver disease," Acta Pharmaceutica Sinica B, vol. 10, no. 1, pp. 3-18, 2020.

[30] M. Gago-Dominguez, X. Jiang, and J. E. Castelao, "Lipid peroxidation, oxidative stress genes and dietary factors in breast cancer protection: a hypothesis," Breast Cancer Research, vol. 9, no. 1, p. 201, 2007.

[31] S. C. Sousa, E. N. Maciel, A. E. Vercesi, and R. F. Castilho, "Ca2+-induced oxidative stress in brain mitochondria treated with the respiratory chain inhibitor rotenone," FEBS Letters, vol. 543, no. 1-3, pp. 179-183, 2003.

[32] P. Gómez-Fernández, A. Urtasun, A. W. Paton et al., "Long interleukin-22 binding protein isoform-1 is an intracellular activator of the unfolded protein response," Frontiers in Immunology, vol. 9, p. 2934, 2018.

[33] B. Yogalakshmi, C. Sathiya Priya, and C. V. Anuradha, "Grape seed proanthocyanidins and metformin combination attenuate hepatic endoplasmic reticulum stress in rats subjected to nutrition excess," Archives of Physiology and Biochemistry, vol. 125, no. 2, pp. 174-183, 2019.

[34] Y. Liu, X. Pan, S. Li et al., "Endoplasmic reticulum stress restrains hepatocyte growth factor expression in hepatic stellate cells and rat acute liver failure model," Chemico-Biological Interactions, vol. 277, pp. 43-54, 2017.
[35] W. Sheng, G. Wang, J. Tang et al., "Calreticulin promotes EMT in pancreatic cancer via mediating $\mathrm{Ca} 2+$ dependent acute and chronic endoplasmic reticulum stress," Journal of Experimental \& Clinical Cancer Research, vol. 39, no. 1, p. 209, 2020.

[36] Q. Zhao, X. Che, H. Zhang et al., "Thioredoxin-interacting protein links endoplasmic reticulum stress to inflammatory brain injury and apoptosis after subarachnoid haemorrhage," Journal of Neuroinflammation, vol. 14, no. 1, p. 104, 2017.

[37] A. Kumar and R. Mittal, "Mapping Txnip: key connexions in progression of diabetic nephropathy," Pharmacological Reports, vol. 70, no. 3, pp. 614-622, 2018.

[38] W. Li, T. Cao, C. Luo et al., "Crosstalk between ER stress, NLRP3 inflammasome, and inflammation," Applied Microbiology and Biotechnology, vol. 104, no. 14, pp. 6129-6140, 2020.

[39] E. Jimi, H. Fei, and C. Nakatomi, "NF-kappaB signaling regulates physiological and pathological chondrogenesis," International Journal of Molecular Sciences, vol. 20, no. 24, 2019.

[40] L. Ma, C. Li, S. Lian et al., "Procyanidin B2 alleviates liver injury caused by cold stimulation through Sonic hedgehog signalling and autophagy," Journal of Cellular and Molecular Medicine, vol. 25, no. 16, pp. 8015-8027, 2021. 